\title{
Non-linear finite element analysis for prediction of seismic response of buildings considering soil-structure interaction
}

\author{
E. Çelebi ${ }^{1}$, F. Göktepe ${ }^{1}$, and N. Karahan ${ }^{2}$ \\ ${ }^{1}$ Engineering Faculty, Department of Civil Engineering, Sakarya University, Sakarya, Turkey \\ ${ }^{2}$ Institute of Science and Technology, Sakarya University, Sakarya, Turkey \\ Correspondence to: E. Çelebi (ecelebi@sakarya.edu.tr)
}

Received: 14 August 2012 - Revised: 30 October 2012 - Accepted: 31 October 2012 - Published: 26 November 2012

\begin{abstract}
The objective of this paper focuses primarily on the numerical approach based on two-dimensional (2-D) finite element method for analysis of the seismic response of infinite soil-structure interaction (SSI) system. This study is performed by a series of different scenarios that involved comprehensive parametric analyses including the effects of realistic material properties of the underlying soil on the structural response quantities. Viscous artificial boundaries, simulating the process of wave transmission along the truncated interface of the semi-infinite space, are adopted in the non-linear finite element formulation in the time domain along with Newmark's integration. The slenderness ratio of the superstructure and the local soil conditions as well as the characteristics of input excitations are important parameters for the numerical simulation in this research. The mechanical behavior of the underlying soil medium considered in this prediction model is simulated by an undrained elastoplastic Mohr-Coulomb model under plane-strain conditions. To emphasize the important findings of this type of problems to civil engineers, systematic calculations with different controlling parameters are accomplished to evaluate directly the structural response of the vibrating soil-structure system. When the underlying soil becomes stiffer, the frequency content of the seismic motion has a major role in altering the seismic response. The sudden increase of the dynamic response is more pronounced for resonance case, when the frequency content of the seismic ground motion is close to that of the SSI system. The SSI effects under different seismic inputs are different for all considered soil conditions and structural types.
\end{abstract}

\section{Introduction}

Extensive research has been produced by the great effort of several academicians and practitioners in the past three decades and observations based on the effects of previous strong earthquakes (Mexico City 1985; Loma Prieta 1989; Kobe 1995; Izmit 1999) on structural damage. They have clearly pointed out that the seismic response behavior of many engineering structures could be significantly affected by deformability of the underlying foundation medium due to deep, soft, soil-related motion amplification (Wolf and Song, 2002). To provide theoretical computing aspect for the design of earthquake resistant systems, the analysis of dynamic soil-structure interaction (SSI) phenomena becomes increasingly important for large-scale massive structures and their foundations, especially for the ones located on relatively soft soil in seismically active zones. In analyzing the actual structural behavior during the earthquake, it is rare case to assume that the seismic input motion, which is experienced by the base of the structure, is the same as the motion that would be obtained at the site under consideration if the structure is not present. The commonly assumed fixed-base system is justified only for structures supported on surface soil having an infinite rigidity. Therefore, the fixed-base structure modeling represents close approximation to the real conditions and is currently defined in several seismic codes as a conservative simplification for the practical engineering applications (Gazetas and Mylonakis, 1998).

Several influential books and many notable research papers concentrated on the problems of dynamic SSI in seismic analysis have been written in the interdisciplinary field involving geotechnical and earthquake engineering. The influences of vibrating soil-foundation coupled system on the 
structural behavior for detailed design of important structures have been a special subject of comprehensive studies related to intersection of structural vibrations and soil dynamics including complex wave propagation and recognized as an important task among researchers and engineers to develop a considerable methodology for the process of the SSI analysis in recent years (Dutta et al., 2004; Kausel, 2010).

Many researchers have primarily dealt with the development of several modeling techniques to efficiently simplify the solution of the wave propagation problems in unbounded nature of geological region. In mathematical modeling of interaction problems under the effect of the incident seismic waves, the direct and substructure methods are currently two major approaches. The substructure method, which is handled on the limitation of linear or equivalent linear system theory, is an appropriate and computationally efficient modeling technique for implementation in contemporary building codes such as National Earthquake Hazards Reduction Program and Applied Technology Council (Veletsos and Nair, 1975). By using this method, the system has been divided into two substructures. The governing equations, describing the dynamic response of the finite superstructure and the unbounded soil, can be analyzed independently with respect to the degree of freedom at the common interface nodes by supplying equilibrium and compatibility conditions. It is required to compute the seismic forces acting on the soilstructure interface based on dynamic-stiffness coefficients that represent the dynamic response of the unbounded soil media through its impedance functions. The effects of the foundation medium on the structural response are commonly simulated by a series of frequency-dependent springs and dashpots representing a theoretical half-space or a simplifying hypothesis of homogeneous horizontal layers surrounding the base of the structure. The noteworthy research papers that deal with the discrete values of impedance functions over wide ranges of frequency-factors have been presented for both surface-supported and embedded foundations resting on soil strata (Luco and Westmann, 1971; Kausel and Roesset, 1974; Gazetas, 1983; Wong and Luco, 1985; Apsel and Luco, 1987; Çelebi and Gündüz, 2005; Mylonakis et al., 2006).

Referring to the direct method, many computational methods such as the finite difference method, the finite element method (FEM), the thin layer-flexible volume method, the boundary element method (BEM) and their coupling procedures for the modeling of unbounded media have been used for the analysis of interaction problems.

In order to analyze the unbounded soil medium included in the superstructure within in the same model, the direct numerical process requires a high computational effort in a single step with a desired accuracy to solve complicated formulations. Therefore, performing an analysis considering SSI without selecting proper special artificial boundaries at the truncated region of the soil is computationally uneconomical and difficult to obtain the exact solution for practical struc- tural engineering problems and for seismic design applications.

The finite element analysis (FEA) is extensively used to establish mathematical models defined by properly selected interpolation functions for finding approximate solutions of partial differential equations and integral equations of coupled systems in civil engineering problems. FEA originated due to the need to solve complex elasticity and plasticity problems by taking the near-field region for analysis to be large and truncating the outer region. As is well known regarding the numerical discretization techniques for infinite domains, only a finite portion of the domain under consideration can be discretized, whereas in numerical treatment of wave propagation and dynamic response analysis of infinite domain, classical finite element discretization does not produce accurate results of its incapability in discretizing whole infinite domain.

To overcome this difficulty, several special types of artificial boundaries with different sensitivities have been proposed and developed to considerably simplify the SSI analysis in the last three decades. Those special types of energy absorbing boundaries, simulating the energy radiation toward the infinite region, are viscous boundary, as stated in the pioneering works by Lysmer and Kuhlemeyer (1969) and White et al. (1977), or transmitting boundary developed by Ang and Newmark (1971) and Kausel and Tassoulas (1981) as energy absorbers for numerical wave motion calculations in time domain. Another alternative to simulate the unbounded media is the infinite element approach employing the displacement shape function with the geometrical decay formulation proposed by Ungless (1973), Zienkiewicz and Bettess (1976) and Bettess (1977) in 1970s. Comprehensive overview of the effect of these boundaries on the finite element solution of soil dynamics problems is given by Roesset and Ettouney (1977).

As an alternative to the FEM, BEM in elasto-dynamics is an effective numerical tool to study such interaction effects. In this approach the energy radiation condition towards infinity is correctly taken into account by the integral equations and the space discretization is reduced to only the boundary of the adjacent medias. The most important contributions have been published by Dominguez and Roesset (1978) based on the frequency domain BEM to compute impedance functions for surface supported rectangular foundations. Published literature reveals several numerical models taking advances of both finite and boundary element approaches, which are called a hybrid method presented by Tzong and Penzien (1983), Yadzchi et al. (1999) and Wolf and Song (1996). In some cases finite model is combined with infinite elements at truncated boundaries on SSI models, handled by Medina and Penzien (1982), Khalili et al. (1997), Kim and Yun (2000) and Seo et al. (2007). Some studies based on a coupling procedure of finite element (FE) and scaled boundary finite element (SBFE) for three-dimensional dynamic analysis of unbounded SSI can be found in Song 
and Wolf (1998) as an effective tool for solving the wave propagation problems in the time domain.

In this study, to further demonstrate in practical applications considering SSI and to show the solutions of this type of problems to structural engineers, a comprehensive seismic analysis based on parametric and systematic investigations has been performed by means of finite element code PLAXIS. Herein, the computational simulation of the wave propagation problem with soil-structure interaction effects is directly achieved by employing 2-D finite element model under plane-strain condition including plastic deformations of the underlying soil medium under Mohr-Coulomb failure criterion. The impact of the structural slenderness, the local soil conditions as well as the frequency content of different input motions are considered to assert the dynamic response of the vibrating soil-structure system.

\section{Numerical model and considered parameters for SSI problem}

Seismic-soil structure interaction analysis of the proposed two-dimensional (2-D) finite element (FE) model by employing PLAXIS (Brinkgreve et al., 2002) software package is executed in the time domain to conduct an extensive parametric investigation on structural response. The mesh geometry, the grid spacing, the finite size of the closed domain as well as wave radiation and soil material play an important role in the numerical analyses. The dynamic stress-strain behavior of soils, which acts highly nonlinear under large amplitude forced vibrations, such as earthquake loading is considerably complex. To simulate adequately the seismic response of soils, the constitutive model adopted should hold the essential characteristics of the soil behavior under cycling loading conditions. Because of its simplicity in applications, the plasticity of the underlying soil in this study is simulated by using Mohr-Coulomb failure criterion under plane-strain conditions.

\subsection{Mohr-Coulomb soil model and problem formulation in $\mathrm{FE}$ analysis}

Linear elastic-perfectly plastic soil material model with a yield surface according to the Mohr-Coulomb failure criterion is implemented in its exact form in the geotechnical finite element code PLAXIS (Brinkgreve and Vermeer, 1998). The soil is initially expected to be elastic and the model generates normal and shear stresses at all Gauss points within the mesh. These stresses are then compared with the MC failure criterion. If the stresses at a particular Gauss point lie within the $\mathrm{MC}$ failure envelope, then that location is assumed to remain elastic, otherwise to be yielding.

The input plasticity parameters required for collapse mechanisms predicted by the MC model are, respectively, the internal friction angle $\phi$, the soil cohesion $c$, and the dilatancy angle $\psi$, which is used to describe the flow rule as an realistic irreversible change in volume during shearing (Smith and Griffith, 1982).

The dynamic equilibrium for the soil-structure system under plane-strain condition can be given as follows:

$\mathbf{M} \ddot{u}(t)+\mathbf{C} \dot{u}(t)+\mathbf{C}^{\infty} \dot{u}(t)+\mathbf{K} u(t)=\tilde{\boldsymbol{F}}(t)$

where $\mathbf{M}$ is the mass matrix and $\mathbf{C}$ the material damping matrix constructed based on Rayleigh damping, which is formulated as a function of the mass and stiffness matrices (Zienkiewicz and Taylor, 1991; Hughes, 1987). In this study, despite of the geometrical damping, which is defined as radiation damping matrix $\mathbf{C}^{\infty}$ having dominant effect, some amount of Rayleigh damping is introduced into the soil to avoid floating errors that may arise out of singularities. In order to overcome the difficulty in obtaining damping coefficients corresponding to adjacent two natural frequencies of vibration without doing resonant column tests, the influence of Rayleigh damping coefficients on structural response is investigated by trial-and-error approach.

$$
\begin{aligned}
& \mathbf{M}=\iint_{\Omega} \boldsymbol{N}^{T} \boldsymbol{N} \rho \partial \Omega \\
& \mathbf{C}=\alpha_{R} \mathbf{M}+\beta_{R} \mathbf{K}= \\
& \alpha_{R} \iint_{\Omega} \boldsymbol{N}^{T} \boldsymbol{N} \rho \partial \Omega+\beta_{R} \iint_{\Omega} \boldsymbol{B}^{T} \boldsymbol{D} \boldsymbol{B} \partial \Omega \\
& \mathbf{C}^{\infty}=\iint_{\Omega} \boldsymbol{N}^{T}\left[\begin{array}{cc}
c_{1} \rho V_{\mathrm{p}} & 0 \\
0 & c_{2} \rho V_{\mathrm{s}}
\end{array}\right] \boldsymbol{N} \partial \Omega
\end{aligned}
$$

The contribution of $\mathbf{M}$ in the material damping $\mathbf{C}$ is dominant only for low-frequency vibrations. The frequency content of the vibrations considered in this analysis rises up to $20 \mathrm{~Hz}$ for considering seismic inputs. To evaluate the effect of beta coefficients, which damped high-frequency vibrations, three different values $(0.1,0.01$ and 0.001$)$ are considered when the $\alpha_{R}$ value is constant. The best fitting damping coefficients are chosen as $\alpha_{R}=0.01$ and $\beta_{R}=0.01$, respectively. Stiffness matrix $\mathbf{K}$ and the vector of equivalent nodal forces $\tilde{\boldsymbol{F}}(t)$ are respectively given by

$$
\begin{aligned}
\mathbf{K} & =\left(\iint_{\Omega} \boldsymbol{B}^{T} \boldsymbol{D} \boldsymbol{B} \partial \Omega\right) \\
\tilde{\boldsymbol{F}}(t) & =\boldsymbol{F}(t)+\boldsymbol{F}^{\infty}(t)= \\
& \iint_{\Omega} \boldsymbol{N}^{T} \boldsymbol{b} \partial \Omega+\iint_{\Gamma} \boldsymbol{N}^{T} t \partial \Gamma- \\
& \left(\iint_{\Omega} \boldsymbol{N}^{T}\left[\begin{array}{cc}
c_{1} \rho V_{\mathrm{p}} & 0 \\
0 & c_{2} \rho V_{\mathrm{s}}
\end{array}\right] \boldsymbol{N} \partial \Omega\right)\left(\dot{\boldsymbol{u}}_{\mathrm{b}}-\dot{\boldsymbol{u}}_{\mathrm{bf}}\right)
\end{aligned}
$$

in which $\rho$ is the mass density of the soil, $V_{\mathrm{p}}$ and $V_{\mathrm{s}}$ are the pressure wave velocity and the shear wave velocity, respectively. Here, $c_{1}$ and $c_{2}$ are relaxation coefficients that 
have been introduced to improve the performance of the absorption at the local viscous boundaries. The interpolation function $\mathbf{N}$ called as displacement field gives the strain displacement transformation matrix $\mathbf{B}$. The density vector of the specified body forces is indicated by $\boldsymbol{b}$, and $\boldsymbol{t}$ is a vector of external traction that may be imposed to surface $\Gamma$, defined in Eq. (6). To considerably simplify the SSI analysis, special boundary conditions, which can absorb the energy waves, are specified along the truncated interfaces of the model boundaries to avoid spurious reflection of waves back into the soil medium. Hereby, $\mathbf{F}(t)^{\infty}$ is the force vector related to the viscous damper on the artificial boundary. $\dot{u}_{\mathrm{b}}$ and $\dot{u}_{\mathrm{bf}}$ are respectively the nodal velocities on the boundary and in the corresponding free field. When plasticity is present, the matrix $\mathbf{K}$ given by Eq. (5) should be the tangential matrix, which indicates the relation between increments of nodal displacement and the resulting increments of nodal load, as below:

$\mathbf{K}_{t}=\left(\iint_{\Omega} \mathbf{B}^{T} \mathbf{D}^{\mathrm{ep}} \mathbf{B} \partial \Omega\right)$

where $\mathbf{D}^{\text {ep }}$ is used in case of $f=0$ and $\partial f=0$, but is replaced by elastic constitutive matrix $\mathbf{D}$ if $f<0$ and $\partial f<0$.

\subsection{Meshing and verification of the proposed SSI model}

To obtain the desired accuracy of the dynamic response of the building with a reasonable computing time and memory requirements, the effect of the discretization size of the proposed soil region, extending to infinite in reality, is examined by considering the structural and free surface response under the earthquake-induced vibration. The accuracy of different FE meshes for SSI model, adopted with energy absorbing boundaries of Lysmer type, is verified by trial-and-error method to achieve a considerable reduction in computational domain.

The representation of the computational and dimension of the problem set to be defined by utilizing the FE mesh, for soil-structure coupled system, is given in Fig. 1. In the analysis, the Loma Prieta (18 October 1989) earthquake ground motion is applied to the bottom of soil along short direction of the building. Two-dimensional 6-node triangular elements are adopted in FE mesh of soil region. This type of element consists of two translational degrees of freedom at each node under plain-strain condition. It provides a fourth-order interpolation for deformed shape associated with the wave lengths in numerical algorithm. The 5-node plate elements representing frame structure are considered to be linear elastic. The considered structure is five-storey reinforced concrete frame with a basement located at a depth of $2 \mathrm{~m}$ below the soil surface. Its height is $15 \mathrm{~m}$ from the ground level and its width is $12 \mathrm{~m}$. The spacing between the columns is assumed to be $4 \mathrm{~m}$. The required material parameters considered in FE model for the underlying soil and structure are summarized in Tables 1 and 2 .

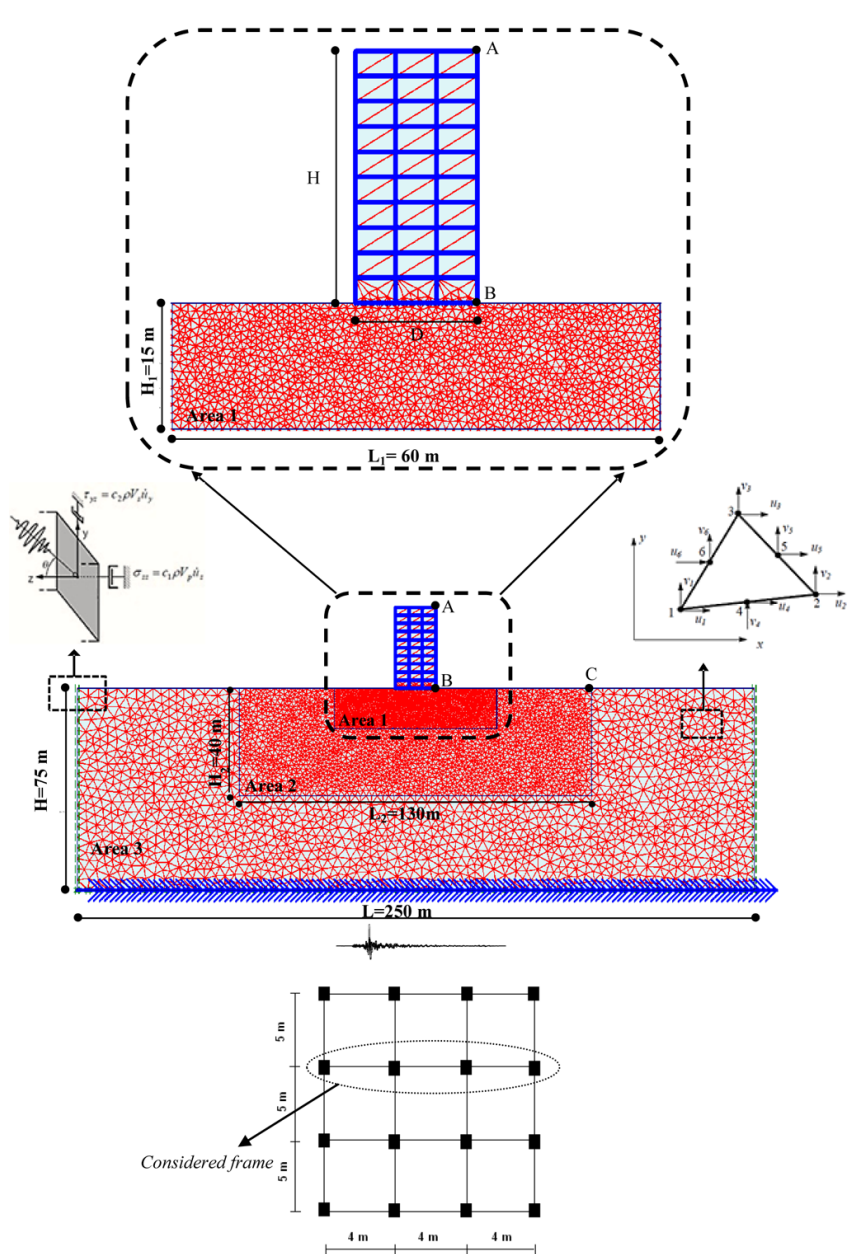

Fig. 1. Finite element mesh considered for the soil-structure interaction system.

The response measurement points in the model are the roof floor level, elevation of which is $15 \mathrm{~m}$, foundation base and free soil surface at a distance of $60 \mathrm{~m}$ from the building, which are described as $A, B$ and $C$, respectively in Fig. 1. Firstly, the lateral extent of the finite soil domain described by $L$ is determined for reliable results of the seismic response behavior at the abovementioned points. In each computational model different values of $L$, ranging from $100 \mathrm{~m}$ to $350 \mathrm{~m}$, have been considered, while keeping the total soil depth constant with $H=50 \mathrm{~m}$. After determining the optimal $L$, the depth of the soil region is investigated. The effect of mesh size on peak values of lateral displacement and acceleration is given comparatively for corresponding points in Fig. 2. The obtained results are also given in Tables 3 and 4, respectively. From this study, the optimal size of computational domain is determined as the lateral extent of $L=200 \mathrm{~m}$ and the total depth of $H=75 \mathrm{~m}$. Furthermore, the FE model extends $119 \mathrm{~m}$ on both sides of the building. Since it is the closest region to the foundation of the superstructure, the finer FE mesh $\left(H_{1}=15 \mathrm{~m}\right.$ and $\left.L_{1}=60 \mathrm{~m}\right)$ is used 
Table 1. Mechanical property of underlying soil (Yang, 1997) for validation of SSI model.

\begin{tabular}{llll}
\hline $\begin{array}{l}\text { Parameter } \\
\text { Soil Type: Sand }\end{array}$ & Symbol & Magnitude & Unit \\
\hline Total unit weight & $\gamma$ & 17.00 & $\left(\mathrm{kN} \mathrm{m}^{-3}\right)$ \\
Young's modulus & $E$ & 34500 & $\left(\mathrm{kN} \mathrm{m}^{-2}\right)$ \\
Shear modulus & $G$ & 13270 & $\left(\mathrm{kN} \mathrm{m}^{-2}\right)$ \\
Poisson's ratio & $v$ & 0.30 & - \\
Compression wave velocity & $V_{\mathrm{p}}$ & 165.2 & $\mathrm{~m} \mathrm{~s}^{-1}$ \\
Shear wave velocity & $V_{\mathrm{S}}$ & 88.32 & $\mathrm{~m} \mathrm{~s}^{-1}$ \\
Void ratio & $e$ & 0.5 & - \\
Cohesion & $c$ & 0 & $\left(\mathrm{kN} \mathrm{m}^{-2}\right)$ \\
Friction angle & $\varnothing$ & 33 & $\left(^{\circ}\right)$ \\
Dilatancy angle & $\psi$ & 3 & $\left({ }^{\circ}\right)$ \\
Interface strength reduction factor & $R_{\text {inter }}$ & 0.67 & - \\
\hline
\end{tabular}

Table 2. Mechanical property of superstructure for validation of SSI Model.

\begin{tabular}{lllll}
\hline Parameter & & Symbol & Unit & Magnitude \\
\hline Columns & Normal stiffness & $E A$ & $(\mathrm{kN})$ & $4.48 \times 10^{6}$ \\
& Flexural rigidity & $E I$ & $\left(\mathrm{kNm}^{2}\right)$ & $5.97 \times 10^{4}$ \\
& Weight & $w$ & $\left(\mathrm{kN} \mathrm{m}^{-2}\right)$ & 10 \\
\multirow{4}{*}{ Girders } & Normal stiffness & $E A$ & $(\mathrm{kN})$ & $5.04 \times 10^{6}$ \\
& Flexural rigidity & $E I$ & $\left(\mathrm{kNm}^{2}\right)$ & $1.51 \times 10^{5}$ \\
& Weight & $w$ & $\left(\mathrm{kN} \mathrm{m}^{-2}\right)$ & 10 \\
\hline
\end{tabular}

in order to transmit all the vibratory wave patterns where the plastic deformations are expected to be formed. This is achieved by employing smaller element size $(\Delta h \leq 1 \mathrm{~m})$, which is defined by the condition that the element size cannot exceed one-eighth to one-fifth of the shortest Rayleigh wavelength at the highest frequency of the significant components of the Fourier response spectrum. The time step integration has been chosen as $\Delta t<0.075 \mathrm{~s}$ taking into account the Courant condition for the FEM simulations (Courant et al., 1967). The mesh of the remaining subzones (hereby, $H_{2}=40 \mathrm{~m}, L_{2}=140 \mathrm{~m} ; \Delta h=2 \mathrm{~m}$ ) has been designed to be relatively coarser than the abovementioned localized domain increasing in size gradually reaching the value of $4 \mathrm{~m}$ (the maximum allowable element size in this case) for distant elements near the lower edge.

\section{Numerical studies and results}

The slenderness ratio, which is defined as the height-to-base width ratio of the superstructure, the underlying soil conditions, the constitutive modeling of the soil behavior as well as the frequency content of the input excitations are the essential parameters that are considered in this study. Four different slenderness ratios $(H / D=0.4,1,2$, and 4$)$, representing squat to slender buildings, are employed in this parametric
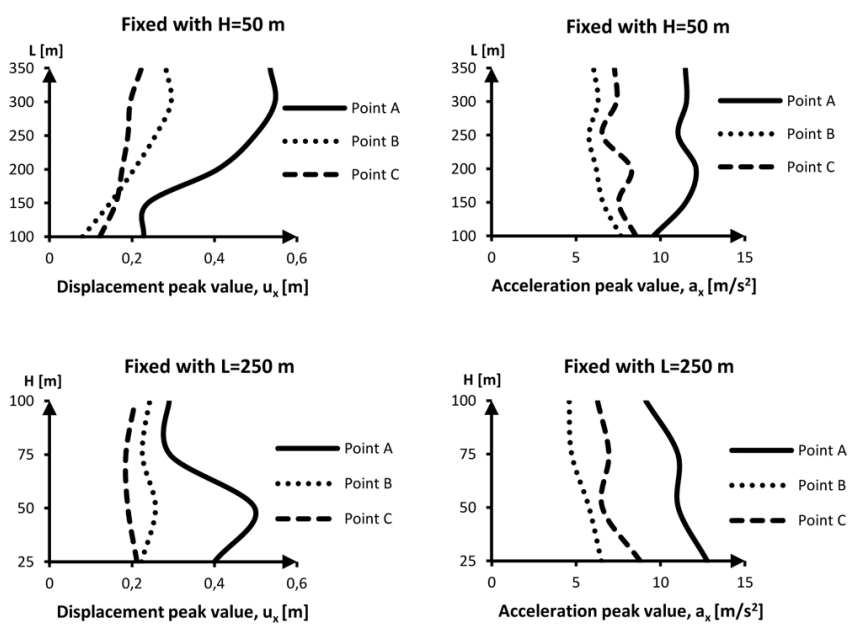

Fig. 2. Effect of mesh size on peak seismic response of proposed SSI model.

analysis. To evaluate the effect of the SSI on the structural response with regard to slenderness ratio of the building, three different types of soil material are considered: loose, medium and firm soil conditions. The mechanical properties of considered frame-type structure and soils are given in Tables 5-8. Both linear-elastic and elastic-perfectly plastic Mohr-Coulomb material models are considered separately for describing the soil behavior for the proposed SSI system. The computational model is tested under three different input motions: Loma Prieta $\left(M_{\mathrm{w}}=6.9\right.$ in 1989, USA), Kocaeli $\left(M_{\mathrm{W}}=7.4\right.$ in 1999 , Turkey), and Erzincan $\left(M_{\mathrm{S}}=6.8\right.$ in 1992, Turkey) earthquake records.

The effects of SSI on the envelopes of peak lateral floor displacement $\left(u_{x}\right)$ of the building for varying slenderness ratios $(H / D=1,2$, and 4) under the excitation of Loma Prieta input wave are shown in Figs. 3-5. The results of analysis for structures with low slenderness ratio $H / D=1$ have considerably changed by ignoring the SSI effect in the 
Table 3. Displacement and acceleration peak values for different points (constant with $H=50 \mathrm{~m}$ ).

\begin{tabular}{|c|c|c|c|c|c|c|c|}
\hline \multicolumn{8}{|c|}{ Underlying soil properties (Yang, 1997) } \\
\hline & & \multicolumn{6}{|c|}{ Length of discretization area $L(H=50 \mathrm{~m})$} \\
\hline & & $100 \mathrm{~m}$ & $150 \mathrm{~m}$ & $200 \mathrm{~m}$ & $250 \mathrm{~m}$ & $300 \mathrm{~m}$ & $350 \mathrm{~m}$ \\
\hline \multirow{4}{*}{ Point A } & $\varkappa_{g x}\left(\mathrm{~ms}^{-2}\right)$ & 9.596 & -11.51 & -12.11 & 11.05 & -11.54 & -11.48 \\
\hline & $\ddot{u}_{g y}\left(\mathrm{~ms}^{-2}\right)$ & 3.880 & -3.898 & 3.267 & -3.741 & -3.536 & -4.432 \\
\hline & $u_{x}(\mathrm{~m})$ & -0.228 & 0.239 & -0.408 & -0.498 & -0.547 & -0.535 \\
\hline & $u_{y}(\mathrm{~m})$ & -0.116 & -0.163 & -0.146 & -0.125 & -0.121 & -0.127 \\
\hline \multirow{4}{*}{ Point B } & $u_{g x}\left(\mathrm{~ms}^{-2}\right)$ & -7.654 & -6.593 & -6.197 & -5.767 & -6.305 & -6.033 \\
\hline & $\ddot{u}_{g y}\left(\mathrm{~m} \mathrm{~s}^{-2}\right)$ & -4.935 & -3.824 & 3.240 & -3.704 & -3.531 & -4.387 \\
\hline & $u_{x}(\mathrm{~m})$ & 0.080 & 0.147 & -0.205 & -0.257 & -0.295 & -0.282 \\
\hline & $u_{y}(\mathrm{~m})$ & -0.115 & -0.160 & -0.145 & -0.125 & -0.120 & -0.125 \\
\hline \multirow{4}{*}{ Point $\mathrm{C}$} & $u_{g x}\left(\mathrm{~m} \mathrm{~s}^{-2}\right)$ & -8.541 & -7.532 & -8.278 & -6.556 & -7.401 & -7.278 \\
\hline & $\ddot{u}_{g y}\left(\mathrm{~m} \mathrm{~s}^{-2}\right)$ & -1.949 & 2.800 & 1.869 & -2.716 & -2.140 & 1.761 \\
\hline & $u_{x}(\mathrm{~m})$ & 0.122 & 0.161 & 0.176 & 0.190 & 0.196 & -0.223 \\
\hline & $u_{y}(\mathrm{~m})$ & -0.120 & -0.086 & -0.062 & -0.073 & -0.081 & -0.072 \\
\hline
\end{tabular}

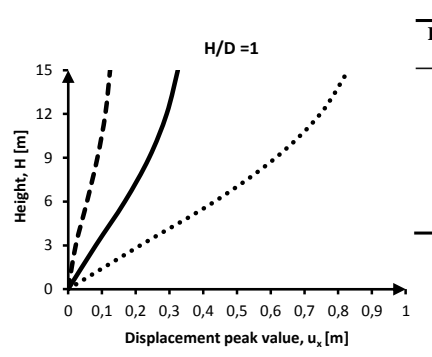

\begin{tabular}{|c|c|c|c|}
\hline Height & $\begin{array}{l}\text { No } \\
\text { SSI } \\
\end{array}$ & $\begin{array}{l}\text { Linear } \\
\text { Elastic }\end{array}$ & $\begin{array}{l}\text { Elasto- } \\
\text { Plastic }\end{array}$ \\
\hline 0 & 0 & 0 & 0 \\
\hline 3 & 0.023 & 0.214 & 0.082 \\
\hline 6 & 0.056 & 0.434 & 0.168 \\
\hline 9 & 0.087 & 0.615 & 0.240 \\
\hline 12 & 0.110 & 0.747 & 0.292 \\
\hline 15 & 0.124 & 0.830 & 0.325 \\
\hline \multicolumn{4}{|c|}{ Elasto-Plastic } \\
\hline & & & Loos \\
\hline
\end{tabular}
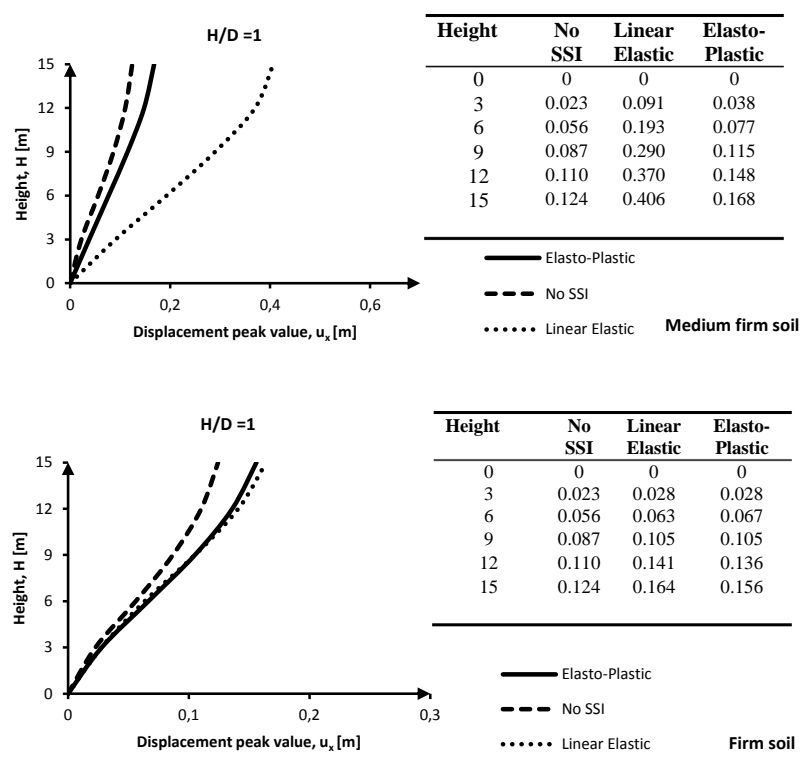

Fig. 3. Variation of peak lateral response of the building depending on different soil conditions in the case of $H / D=1$ for the 1989 Loma Prieta earthquake input motion.
Table 4. Displacement and acceleration peak values for different points (constant with $L=250 \mathrm{~m}$ ).

\begin{tabular}{llrrrr}
\hline \multicolumn{6}{c}{ Underlying soil properties (Yang, 1997) } \\
\hline & & \multicolumn{5}{c}{ Depth of discretization area $H(L=250 \mathrm{~m})$} \\
\cline { 3 - 6 } & & $25 \mathrm{~m}$ & $50 \mathrm{~m}$ & $75 \mathrm{~m}$ & $100 \mathrm{~m}$ \\
\hline \multirow{4}{*}{ Point A } & $\ddot{u}_{g x}\left(\mathrm{~m} \mathrm{~s}^{-2}\right)$ & -12.76 & 11.05 & -11.02 & -9.126 \\
& $\ddot{u}_{g y}\left(\mathrm{~m} \mathrm{~s}^{-2}\right)$ & -4.332 & -3.741 & -3.701 & 3.109 \\
& $u_{x}(\mathrm{~m})$ & 0.400 & -0.498 & 0.292 & -0.290 \\
& $u_{y}(\mathrm{~m})$ & -0.180 & -0.125 & -0.125 & -0.089 \\
\hline \multirow{4}{*}{ Point B B } & $\ddot{u}_{g x}\left(\mathrm{~m} \mathrm{~s}^{-2}\right)$ & -6.496 & -5.767 & 4.737 & -4.588 \\
& $\ddot{u}_{g y}\left(\mathrm{~m} \mathrm{~s}^{-2}\right)$ & -4.242 & -3.704 & -3.765 & 3.030 \\
& $u_{x}(\mathrm{~m})$ & -0.223 & -0.257 & 0.225 & 0.243 \\
& $u_{y}(\mathrm{~m})$ & -0.179 & -0.125 & -0.124 & -0.088 \\
\hline \multirow{5}{*}{ Point C } & $\ddot{u}_{g x}\left(\mathrm{~m} \mathrm{~s}^{-2}\right)$ & -8.790 & -6.556 & -6.941 & -6.263 \\
& $\ddot{u}_{g y}\left(\mathrm{~m} \mathrm{~s}^{-2}\right)$ & 1.447 & -2.716 & 1.511 & -0.833 \\
& $u_{x}(\mathrm{~m})$ & 0.212 & 0.190 & 0.185 & 0.208 \\
& $u_{y}(\mathrm{~m})$ & -0.030 & -0.073 & -0.090 & 0.113 \\
\hline
\end{tabular}

case of loose soil with $V_{\mathrm{s}}=90 \mathrm{~m} \mathrm{~s}^{-1}$. By examining the curves given in Fig. 3, it may be noted that the SSI considered with plasticity effect causes an increase up to 2.6 times on the lateral roof displacement compared to those of the fixed-base support, whereas the corresponding values increase up to $25 \%$ for stiffer soil conditions. As it can be seen from Figs. 4 and 5 for structures having $H / D=2$ and 4 , the structural response increases 3 times and 1.8 times respectively, when compared with fixed-base support. It is remarkable to state that the maximum response occurs for intermediate slender structures with $H / D=2$, which represents the 10-storey building. That means the structural response will be amplified when the frequency content of 

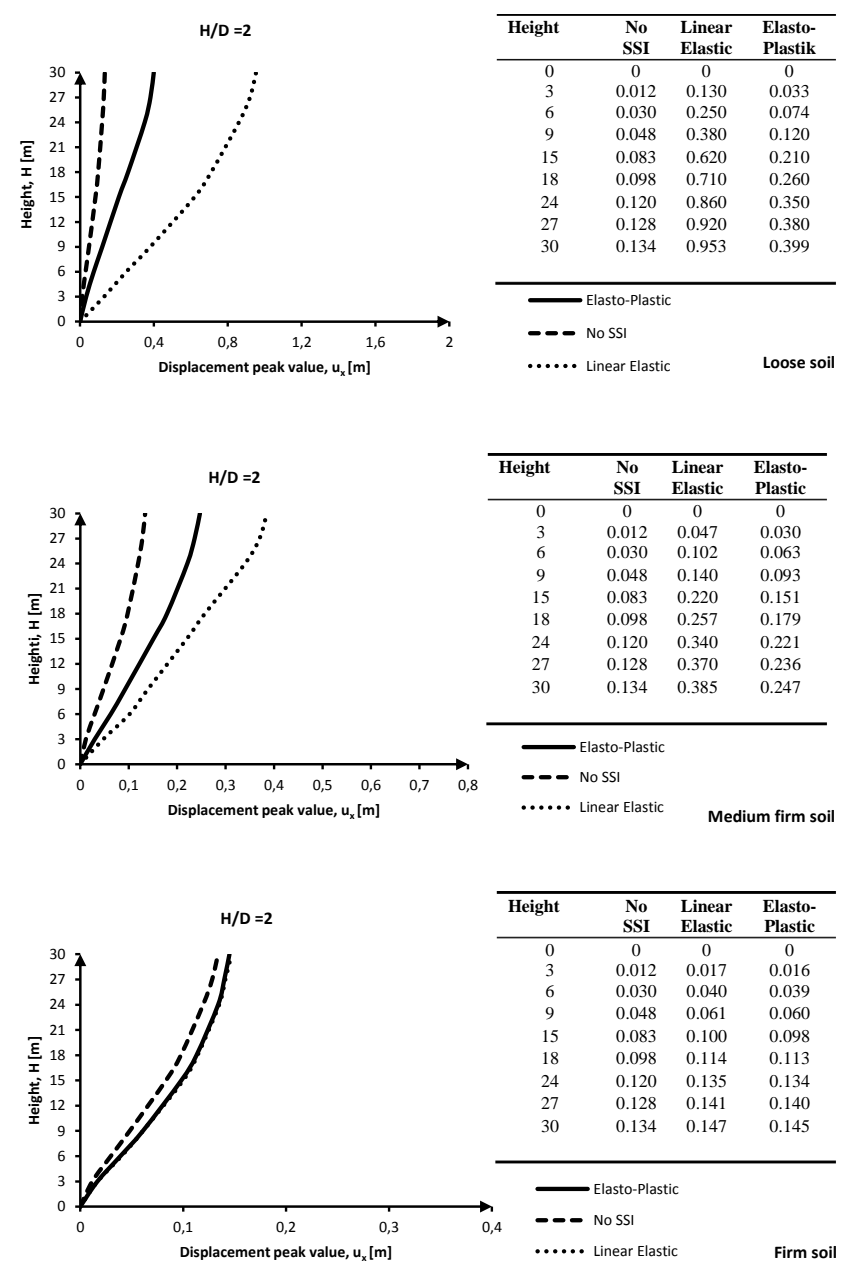

Fig. 4. Variation of peak lateral response of the building depending on different soil conditions in the case of $H / D=2$ for the 1989 Loma Prieta earthquake input motion.

the seismic ground motion is close to that of the SSI system. No significant change is observed in the case of firm soil with $V_{\mathrm{s}}=1000 \mathrm{~m} \mathrm{~s}^{-1}$ when compared with fixed base condition. The maximum change is $20 \%$ for slender structures with $H / D=4$. It can be seen that an apparent decrease occurs in displacements when compared to those obtained rigidly based structures, as the shear wave velocity of the soil medium increases. As expected, when SSI is taken into account, the constitutive models assumed for underlying soil play an important role on the seismic structural response. Linear elastic soil model leads to larger values of peak displacements with respect to Mohr-Coulomb soil model. For instance, the elastic behavior assumption for soft soil condition increases to 2.55 times the roof lateral displacement of the squat building with $H / D=1$, whereas this corresponding value decreases to almost 1.1 times for slender structures. Furthermore, the soil materials model chosen for numerical analysis becomes negligible for firm soil conditions, as
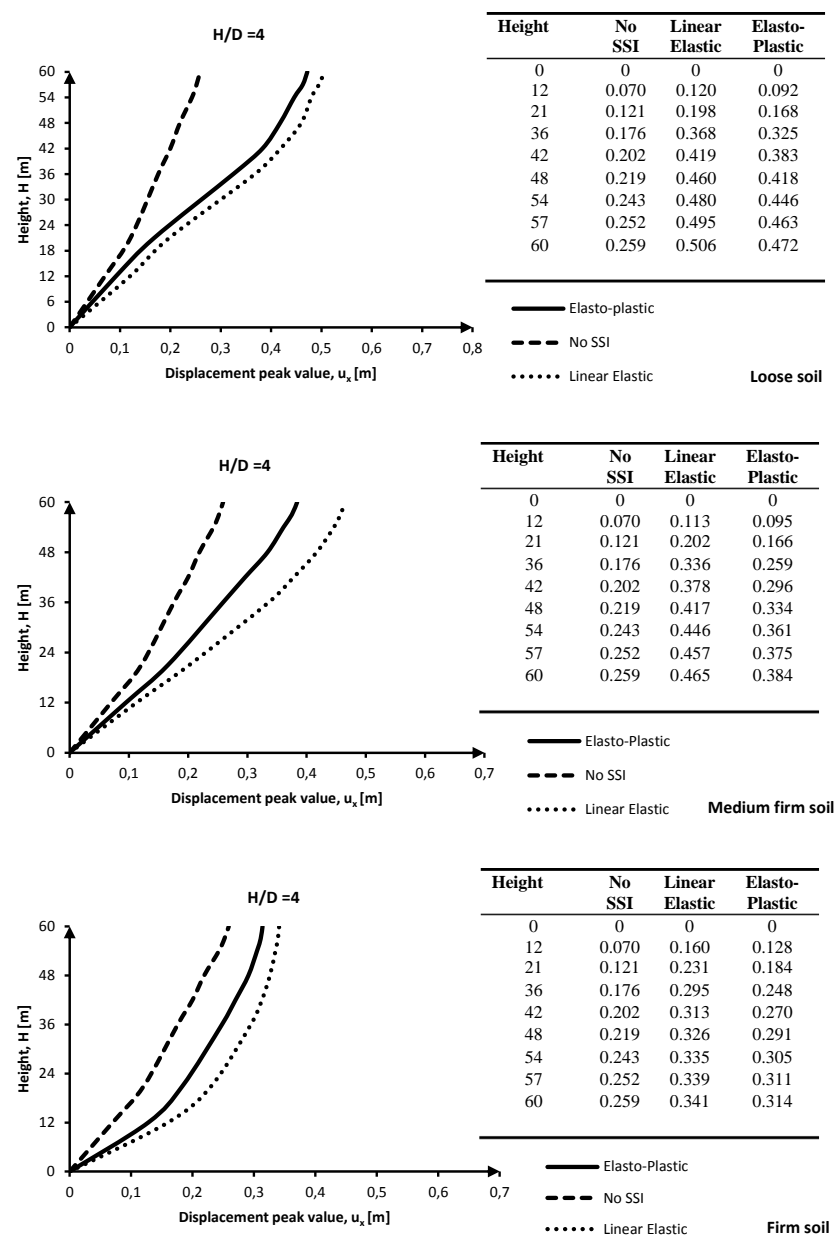

Fig. 5. Variation of peak lateral response of the building depending on different soil conditions in the case of $H / D=4$ for the 1989 Loma Prieta earthquake input motion.

the slenderness ratio increases. The maximum difference between the compared values does not exceed $20 \%$.

The plots of time histories for the lateral displacements at the roof floor level of the squat $(H / D=0.4)$ and slender buildings $(H / D=4)$ located on different soil conditions under consideration of SSI with plasticity effect are compared with a fixed-base structures in Figs. 6-7, for Loma Prieta input motion. From these time-domain responses, it is observed that the SSI appears to be more significant in affecting squat structures $(H / D \leq 1)$. However, as the time period of the structure is increased, the SSI effects are reduced. For structures having slenderness ratio of $H / D=0.4$ and $H / D=4$, the lateral peak displacements increase 3.5 times and 1.5 times, respectively in the case of soft soil conditions compared to the associated fixed-base conditions.

Unlike the abovementioned excitation applied as ground motion for proposed SSI model, Kocaeli and Erzincan earthquake records are also employed for analyzing the seismic response of structures. The variation of peak top floor 

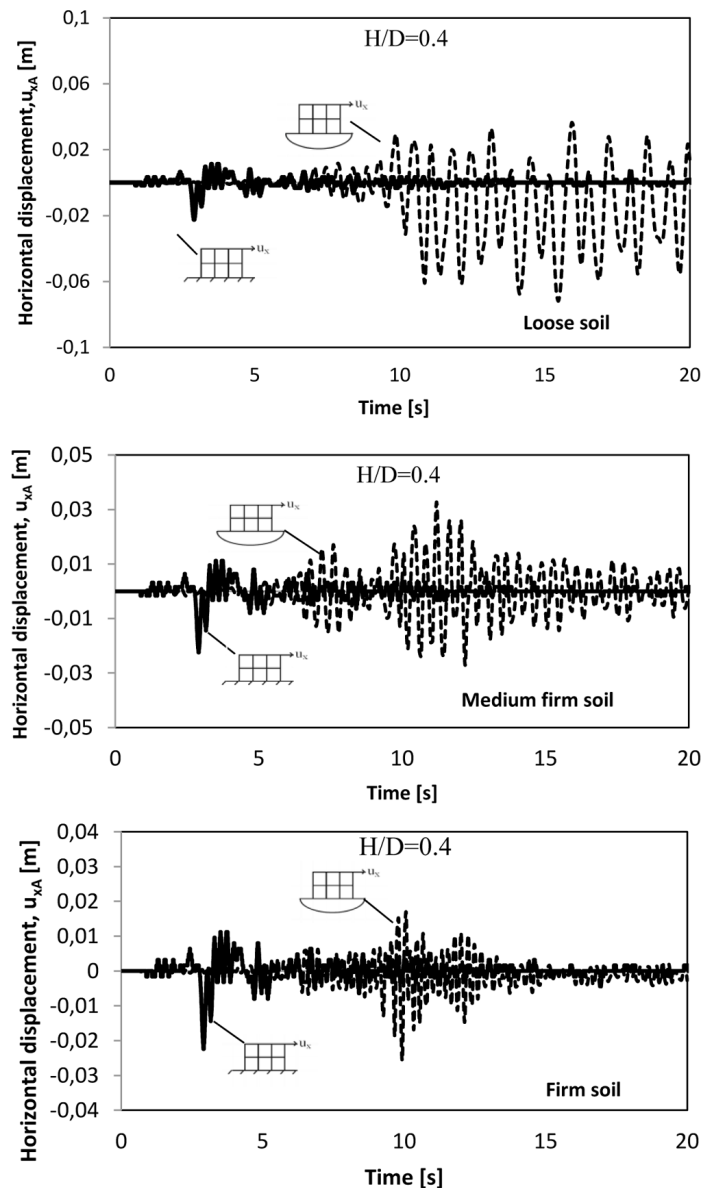

Fig. 6. Variation of lateral displacement time histories at the roof floor of the buildings under consideration of SSI (dashed curves) and fixed-base support (solid curves) in the case of $H / D=0.4$ with different soil conditions for the 1989 Loma Prieta earthquake input motion.

Table 5. Material parameters for superstructure considered in FE analysis.

\begin{tabular}{lllll}
\hline Parameter & & Symbol & Unit & Magnitude \\
\hline \multirow{2}{*}{ Columns } & Normal stiffness & $E A$ & $(\mathrm{kN})$ & $1.191 \times 10^{7}$ \\
& Flexural rigidity & $E I$ & $\left(\mathrm{kNm}^{2}\right)$ & 156420 \\
Girders & Normal stiffness & $E A$ & $\left(\mathrm{kN}^{-2}\right.$ & $1.191 \times 10^{7}$ \\
& Flexural rigidity & $E I$ & $\left(\mathrm{kN} \mathrm{m}^{-2}\right)$ & 156420 \\
& Weight & $w$ & $\left(\mathrm{kN} \mathrm{m}^{-2}\right)$ & 50 \\
\hline
\end{tabular}

displacements $\left(u_{x}\right)$ with respect to slenderness ratio $(H / D)$ is given in Fig. 8 for all soil conditions and seismic inputs considered in the dynamic SSI problem. Herein, the material deformation of the underlying soil medium is described with respect to Mohr-Coulomb failure criterion. For all soil conditions, the seismic structural response under Erzincan earthquake is clearly greater than those obtained under the Kocaeli and Loma Prieta earthquakes in the case of $H / D>1.5$. From studying these curves, it may be stated that the lat-
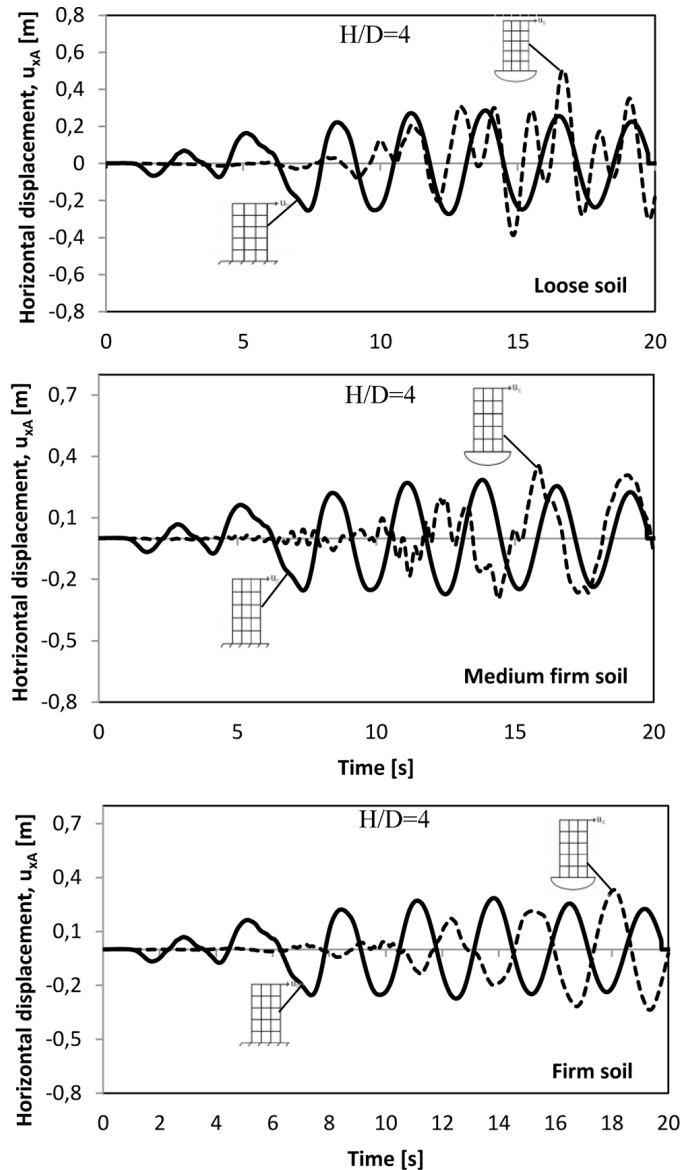

Fig. 7. Variation of lateral displacement time histories at the roof floor of the buildings under consideration of SSI (dashed curves) and fixed-base support (solid curves) in the case of $H / D=4$ with different soil conditions for the 1989 Loma Prieta earthquake input motion.

Table 6. Material parameters of Mohr-Coulomb model for loose soil considered in FE analysis.

\begin{tabular}{|c|c|c|c|}
\hline Parameter & Symbol & Magnitude & Unit \\
\hline Total unit weight & $\gamma$ & 16.67 & $\left(\mathrm{kN} \mathrm{m}^{-3}\right)$ \\
\hline Young's modulus & $E$ & $3.45 \times 10^{4}$ & $\left(\mathrm{kN} \mathrm{m}^{-2}\right)$ \\
\hline Shear modulus & $G$ & $1.38 \times 10^{4}$ & $\left(\mathrm{kN} \mathrm{m}^{-2}\right)$ \\
\hline Poisson's ratio & $v$ & 0.25 & - \\
\hline Compression wave velocity & $V_{\mathrm{p}}$ & 156.00 & $\mathrm{~ms}^{-1}$ \\
\hline Shear wave velocity & $V_{\mathrm{s}}$ & 90.00 & $\mathrm{~ms}^{-1}$ \\
\hline Cohesion & $c$ & 0 & $\left(\mathrm{kN} \mathrm{m}^{-2}\right)$ \\
\hline Friction angle & $\varnothing$ & 33 & $\left({ }^{\circ}\right)$ \\
\hline Dilatancy angle & $\psi$ & 3 & $\left({ }^{\circ}\right)$ \\
\hline Interface strength reduction factor & $R_{\text {inter }}$ & 0.67 & - \\
\hline
\end{tabular}

eral peak displacement in the case of loose soils for slender structures $(H / D=4)$ under consideration of Erzincan excitation is 1.2 times and 2.2 times bigger than those under Kocaeli and Loma Prieta excitations, respectively. Furthermore, the corresponding value is 1.6 times and 1.3 times bigger 
Table 7. Material parameters of Mohr-Coulomb model for medium firm soil considered in FE analysis.

\begin{tabular}{llll}
\hline Parameter & Symbol & Magnitude & Unit \\
\hline Total unit weight & $\gamma$ & 18.64 & $\left(\mathrm{kN} \mathrm{m}^{-3}\right)$ \\
Young's modulus & $E$ & $3.61 \times 10^{5}$ & $\left(\mathrm{kN} \mathrm{m}^{-2}\right)$ \\
Shear modulus & $G$ & $1.38 \times 10^{5}$ & $\left(\mathrm{kN} \mathrm{m}^{-2}\right)$ \\
Poisson's ratio & $v$ & 0.30 & - \\
Compression wave velocity & $V_{\mathrm{p}}$ & 505.50 & $\mathrm{~m} \mathrm{~s}^{-1}$ \\
Shear wave velocity & $V_{\mathrm{S}}$ & 270.00 & $\mathrm{~m} \mathrm{~s}^{-1}$ \\
Cohesion & $c$ & 0 & $\left(\mathrm{kN} \mathrm{m}^{-2}\right)$ \\
Friction angle & $\phi$ & 35 & $\left({ }^{\circ}\right)$ \\
Dilatancy angle & $\psi$ & 5 & $\left(^{\circ}\right)$ \\
Interface strength reduction factor & $R_{\text {inter }}$ & 0.67 & - \\
\hline
\end{tabular}

Table 8. Material parameters of Mohr-Coulomb model for firm soil considered in FE analysis.

\begin{tabular}{llll}
\hline Parameter & Symbol & Magnitude & Unit \\
\hline Total unit weight & $\gamma$ & 20.64 & $\left(\mathrm{kN} \mathrm{m}^{-3}\right)$ \\
Young's modulus & $E$ & $5.68 \times 10^{6}$ & $\left(\mathrm{kN} \mathrm{m}^{-2}\right)$ \\
Shear modulus & $G$ & $2.10 \times 10^{6}$ & $\left(\mathrm{kN} \mathrm{m}^{-2}\right)$ \\
Poisson's ratio & $v$ & 0.35 & - \\
Compression wave velocity & $V_{\mathrm{p}}$ & 2082.00 & $\mathrm{~m} \mathrm{~s}^{-1}$ \\
Shear wave velocity & $V_{\mathrm{S}}$ & 1000.00 & $\mathrm{~m} \mathrm{~s}^{-1}$ \\
Cohesion & $c$ & 30 & $\left(\mathrm{kN} \mathrm{m}^{-2}\right)$ \\
Friction angle & $\phi$ & 38 & $\left(^{\circ}\right)$ \\
Dilatancy angle & $\psi$ & 8 & $\left(^{\circ}\right)$ \\
Interface strength reduction factor & $R_{\text {inter }}$ & 0.67 & - \\
\hline
\end{tabular}

than abovementioned seismic inputs for stiffer soil conditions, respectively. For structures with $H / D=4$, the relative error between displacement peak value under consideration of SSI and under rigid base support assumption is $5 \%$ (Erzincan earthquake), $93 \%$ (Kocaeli earthquake), $82 \%$ (Loma Prieta earthquake) for loose soil with $V_{\mathrm{s}}=90 \mathrm{~m} \mathrm{~s}^{-1}$. The same comparison is $140 \%$ (Erzincan earthquake), $76 \%$ (Kocaeli earthquake), $21 \%$ (Loma Prieta earthquake) for firm soil with $V_{\mathrm{s}}=1000 \mathrm{~m} \mathrm{~s}^{-1}$, respectively.

For squat structures $(H / D=1)$ located on loose soils, the corresponding peak displacement under consideration of Loma Prieta earthquake is 1.2 times and 2.2 times bigger than that obtained under the excitation of Kocaeli and Erzincan earthquakes, respectively. In the case of firm soil conditions, these rates increase up to 5.8 times and 6.8 times, respectively. For structures having slenderness ratio of $H / D=1$, the abovementioned relative error is $40 \%$ (Erzincan earthquake), $575 \%$ (Kocaeli earthquake), $162 \%$ (Loma Prieta earthquake) for loose soil with $V_{\mathrm{s}}=90 \mathrm{~m} \mathrm{~s}^{-1}$ and $282 \%$ (Erzincan earthquake), $50 \%$ (Kocaeli earthquake), $26 \%$ (Loma Prieta earthquake) for firm soil with $V_{\mathrm{s}}=1000 \mathrm{~m} \mathrm{~s}^{-1}$, respectively.

As it can be seen from the analysis results, each of squat and slender structures gives different seismic response to earthquake ground motions considered in SSI system.

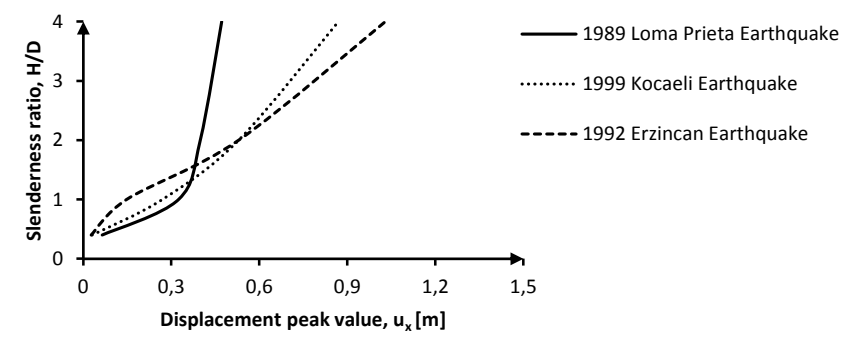

Loose soil

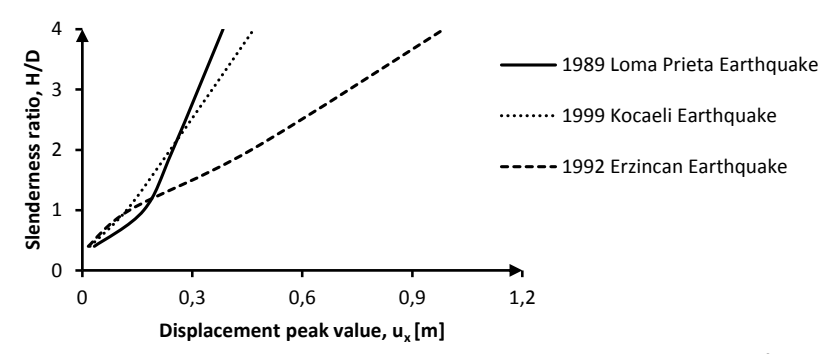

Medium firm soil

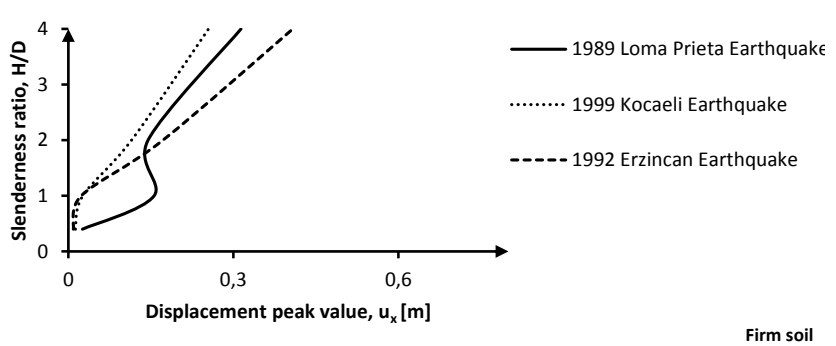

Fig. 8. The variation of peak lateral displacements for top floor with respect to slenderness ratio $(H / D)$ under different seismic inputs.

\section{Concluding remarks}

In this study, the computational simulation of the wave propagation problem with soil-structure interaction effects is directly achieved by employing 2-D finite element model under plane-strain condition including plastic deformations of the underlying soil medium under Mohr-Coulomb failure criterion. The structural slenderness, the underlying soil conditions, the constitutive modeling of the soil behavior as well as the frequency content of the input motions are represented as government parameters. To emphasize the important findings of this type of problems to civil engineers, systematic calculations with different controlling parameters are accomplished to evaluate directly the structural response of the vibrating soil-structure system.

Based on the numerical results, the following conclusions can be drawn:

1. The obtained results indicate that the seismic response of the structures with a few stories has considerably changed by ignoring the SSI effect in the case of loose 
soil with $V_{\mathrm{s}}=90 \mathrm{~m} \mathrm{~s}^{-1}$. This soil-structure coupling appears to be more significant in affecting the lateral deflections of the squat structures compared with the slender structures. In the same manner under different excitations, the supporting firm soils, characterized by $V_{\mathrm{s}}=1000 \mathrm{~m} \mathrm{~s}^{-1}$, do influence considerably the seismic response behavior.

2. Although the effects of the SSI on the structural deformations are considered insignificant in comparison with the fixed base support when the underlying soil becomes stiffer, the frequency content of the seismic motion has a major role in altering the seismic response. The sudden increase of the dynamic response is more pronounced for resonance case, when the frequency content of the seismic ground motion is close to that of the SSI system. Therefore, the SSI effects under different seismic inputs are different for all considered soil conditions and structural types.

3. The constitutive material models assumed for underlying soft soil play an important role on the seismic structural response. It should be noted that there is a great difference between analysis results under condition of linear elastic soil model and Mohr-Coulomb soil model, which captures the essential characteristics of the soil behavior under cycling loading. On the other hand, the soil materials chosen become negligible for firm soil conditions, as the slenderness ratio increases.

Edited by: M. E. Contadakis

Reviewed by: two anonymous referees

\section{References}

Ang, A. H. and Newmark, N. M.: Development of a transmitting boundary for numerical wave motion calculations, Report to Defence Atomic Support Agency, Contract DASA-01-0040, Washington, DC, 1971.

Apsel, R. J. and Luco, J. E.: Impedance functions for foundations embedded in a layered medium: an integral equation approach, J. Earthq. Eng. Struct. Dyn., 15, 213-231, 1987.

Bettess, P.: Infinite elements, Int. J. Num. Meth. Eng., 11, 53-64, 1977.

Brinkgreve, R. B. J. and Vermeer, P. A.: Plaxis Manual Version 7, Rotterdam, A.A. Balkema, 1998.

Brinkgreve, R. B. J., Al-Khoury, R., Bakker, K. J., Bonnier, P. G., Brand, P. J. W., Broere, W., Burd, H. J., Soltys, G., Vermeer, P. A., and Haag, D. D.: Plaxis finite element code for soil and rock analyses, Balkema Publisher, The Netherlands, 2002.

Çelebi, E. and Gündüz, A. N.: An efficient seismic analysis procedure for torsionally coupled multistory buildings including soilstructure interaction, Turkish J. Eng. Environ. Sci., 29, 143-157, 2005.

Courant, R., Friedrichs, K., and Lewy, H.: On the Partial Difference Equations of Mathematical Physics, IBM J., 11, 215-234, 1967.
Dominguez, J. and Roesset, J. M.: Dynamic stiffness of rectangular foundations, Res. Rept. R78 20, Dept. of Civ. Eng., Massachusetts Inst. Tech., Cambridge, Mass, 1978.

Dutta, C. H., Bhattacharya, K., and Roy, R.: Response of lowrise buildings under seismic ground excitation incorporating soilstructure interaction, Soil Dyn. Earthq. Eng., 24, 893-914, 2004.

Gazetas, G.: Analysis of machine foundation vibrations: State of the art, Soil Dyn. Earthq. Eng., 3, 2-42, 1983.

Gazetas, G. and Mylonakis, G.: Seismic soil-structure interaction: new evidence and emerging issues, Geotechnical Earthquake Engineering and Soil Dynamics 3: proceedings of speciality conference (ASCE), 1119-1174, 1998.

Hughes, T. J. R.: The finite element method, Prentice-Hall, 1987.

Kausel, E.: Early history of soil-structure interaction, Soil Dyn. Earthq. Eng., 30, 822-832, doi:10.1016/j.soildyn.2009.11.001, 2010.

Kausel, E. and Roesset, J. M.: Soil-structure interaction problems for nuclear containment structures, Electric Power and the Civil Engineering, in: Proceedings of the ASCE Power Division Conference, Boulder, Colorado, 1974.

Kausel, E. and Tassoulas, J. L.: Transmitting Boundaries: A Closed Form Comparison, Bull. Seism. Soc. America, 71, 143-159, 1981.

Khalili, N., Valiappan S., Tabatabaie Yazdi, J., and Yazdchi M.: 1D infinite element for dynamic problems in saturated media, Comm. Num. Meth. Eng., 13, 727-738, 1997.

Kim, D. K. and Yun, C. B.: Time domain soil-structure interaction analysis in two dimensional medium based on analytical frequency-dependent infinite elements, Int. J. Num. Meth. Eng., 47, 1241-1261, 2000.

Luco, J. E. and Westmann, R. A.: Dynamic response of circular footings, J. Eng. Mech., ASCE, 97, 1381-1395, 1971.

Lysmer, J. and Kuhlemeyer, R. L.: Finite Dynamic Model for Infinite Media, J. Eng. Mech. Div., 95, 859-877, 1969.

Medina, F. and Penzien, J.: Infinite elements for elastodynamics, Earthq. Eng. Struct. Dyn., 10, 699-709, 1982.

Mylonakis, G., Nikolaou, S., and Gazetas, G.: Footings under Seismic Loading: Analysis and Design Issues with Emphasis on Bridge Foundations, Soil Dyn. Earthq. Eng., 26, 824-853, 2006.

Roesset, J. M. and Ettouney, M. M.: Transmitting boundaries: A comparison, Int. J. Numer. Anal. Meth. Geomech., 1, 151-176, 1977.

Seo, C. G., Yun, C. B., and Kim, J. M.: Three-dimensional frequency dependent infinite elements for soil-structureinteraction, Eng. Struct., 29, 3106-3120, 2007.

Smith, I. M. and Griffith, D .V.: Programming the Finite Element Method, 2nd Edn., John Wiley \& Sons, Chisester, UK, 1982.

Song, C. M. and Wolf, J. P.: The scaled boundary finite-element method: analytical solution in frequency domain, Comput. Meth. Appl. Mech. Eng., 164, 249-64, 1998.

Tzong, T.-J. and Penzien, J.: Hybrid modeling of soil-structure interaction in layered media, Report no. UCB/EERC-83/22, EERC, University of California, Berkeley, 1983.

Ungless, R. F.: Infinite elements, M.A. Sc. Dissertation, University of British Columbia, 1973.

White, W., Valliappan, S., and Lee, I. K.: Unified Boundary Finite Dynamic Models, J. Eng. Mech. Div., ASCE, 103, 949-964, 1977. 
Wolf, J. P. and Song, C.: Finite-element modeling of unbounded media, England, Wiley, 1996.

Wolf, J. P. and Song, C.: Some cornerstones of dynamic soilstructure interaction, Eng. Struct., 24, 13-28, 2002.

Wong, H. L. and Luco, J. E.: Tables of Impedance Functions for Square Foundations on Layered Media, Soil Dyn. Earthq. Eng., 4, 64-81, 1985.

Veletsos, A. S. and Nair V. V.: Seismic interaction of structures on hysteretic foundations, J. Struct. Eng., ASCE, 101, 109-129, 1975.

Yang, Z.: Finite Element Simulation of Response of Buried Shelters to Blast Loadings, Fin. Elem. Anal. Des., 24, 113-132, 1997.
Yazdchi, M., Khalili, N., and Valliappan, S.: Dynamic soilstructure interaction analysis via coupled finite-elementboundary-element method, Soil Dyn. Earthq. Eng., 18, 499-517, 1999.

Zienkiewicz, O. C. and Bettess, P.: Infinite Elements in the Study of Fluid-Structure Interaction Problems, Second International Symposium on Computing Methods in Applied Science and Eng., Versailles, France, 1975 (also, Lecture Notes in Physics, 58, 133172, Springer Verlag, 1976).

Zienkiewicz, O. C. and Taylor, R.: The finite element method, 4th Edn., 1-2, McGraw-Hill, London, 1991. 